\title{
Status Loss: The Burden of Positively Selected Immigrants
}

\author{
Per Engzell ${ }^{1,2}$ and Mathieu Ichou ${ }^{3}$ \\ ${ }^{1}$ Nuffield College, University of Oxford \\ ${ }^{2}$ Swedish Institute for Social Research, Stockholm University \\ ${ }^{3}$ Institut National d'Études Démographiques, Paris
}

Manuscript to appear in International Migration Review

April 2019

\begin{abstract}
Immigrants experience an ambiguous social position: on the one hand, they tend to be positively selected on resources from the origin country; on the other, they often occupy the lower rungs of the status ladder in receiving countries. This study explores the implications of this ambiguity for two important individual outcomes: subjective social status and perceived financial situation. We study the diverse sample of immigrants in the European Social Survey and use the fact that, due to country differences in educational distributions, a given education level can entail a very different rank in the sending and receiving countries. We document a robust relationship whereby immigrants who ranked higher in the origin than in the destination country see themselves as being comparatively worse off. This finding suggests that the social position before migration provides an important reference point by which immigrants judge their success in the new country.
\end{abstract}


Immigrant incorporation is a central issue facing Western societies today, and a large literature has arisen to assess its success in domains such as the labor market, intergenerational mobility, or health (Heath and Cheung 2007; Crul and Mollenkopf 2012; Alba and Foner 2015; Abraído-Lanza, Echeverría, and Flórez 2016). However, research on immigrants' social and economic position is incomplete as long as it does not study how immigrants themselves perceive their position. Subjective social status is an important outcome in its own right, but also a crucial predictor of other outcomes such as health (Adler, Epel, Castellazzo, and Ickovics 2000; Anderson, Kraus, Galinsky, and Keltner 2012). Here, we explore how immigrants' cumulative experience of social status from origin to destination shapes their subjective social status and perceived financial situation. To our knowledge, ours is the first study to test the subjective dimension of migrants' transnational status inconsistency: the discrepancy between their social status in sending and receiving countries. By doing so, we answer calls for examining the importance of reference groups - whom immigrants compare themselves to and how - in judging their success in the new country (Gelatt 2013; Akay et al. 2017).

Theoretically, immigrants face an ambiguous social position in the destination country. On the one hand, they often occupy low-skilled and low-paid jobs at the bottom rungs of the status ladder (Alba and Foner 2015). On the other, they may be positively selected on education or material resources from the origin country and bring high ambitions (Feliciano 2005; Ichou 2014). Positive selection can act as a buffer against adverse outcomes, but it might also lead to feelings of frustration or relative deprivation if the status attained in the new country falls short of the one experienced before migration (Schaeffer 2018). Drawing on both quantitative and qualitative research, we formulate and test a number of hypotheses on the role of the difference between immigrants' positions at origin and destination in shaping their current subjective social status. We contrast the notion that high 
social status at origin may buffer against adverse outcomes with the view that downward mobility in migration instead deflates the self-perceived status of highly selected immigrants.

Our analysis draws on six waves of European Social Survey (ESS) data covering 7,673 immigrant respondents. To proxy for pre-migration status, we construct a measure of educational selectivity - an individual's percentile rank in the education distribution of his/her gender and birth cohort in the origin country - for immigrants across 18 European countries and more than 100 origin countries. We complement this measure with a corresponding measure within the receiving country, as well as data on current income, occupation, and social class. We assess the role of these variables for two related outcomes: subjective social status and perceived financial situation. In robustness analyses, we rule out that our results are driven by the idiosyncratic experiences of any one origin or destination country. Moreover, we show that our findings hold across a range of alternative modelling strategies, including diagonal reference models designed to tease apart experiences of social mobility from its constituent components (Sobel 1981).

In our analysis, we find that educational position at origin as such does not predict self-perceived status over and above current economic conditions. However, the difference between the educational rank at origin and destination does. This finding turns out to be driven by positional loss: migrants who are more highly educated by origin-country than by host-country standards make less optimistic assessments of their current situation than do other immigrants in otherwise-similar circumstances. In other words, our results support the idea that status loss from origin to destination shapes immigrants' self-perceptions, rather than high origin status acting as a buffer against feelings of dissatisfaction. We interpret this finding as suggesting that immigrants' pre-migration position provides a reference point by which they judge their success in the new country. To that extent, being highly selected from 
the origin country may be a mixed blessing - raising aspirations, but with them the opportunities for success and frustration alike.

These findings shed new light on established narratives that have tended to see high selectivity as a resource, always protective of inferior outcomes (Borjas 1987; Chiswick 1999; Feliciano 2006; Ichou 2014; Kennedy, Kidd, McDonald, and Biddle 2015). By contrast, our study presents a sobering corrective, speaking to the frustrations confronting those who have abandoned privileged positions in their homeland. Ultimately, our findings recommend a more nuanced and conditional view of immigrant selectivity: high educational selectivity may provide individuals with the resources and ambitions to strive for their socioeconomic advancement. Yet, these resources will be effective only insofar as they are transferable and the receiving society offers sufficient opportunities. Otherwise, the hopes and expectations associated with high pre-migration status might be shattered by the harsh realities of the destination society.

\section{Background and Hypotheses}

Reference groups in social comparison

It has long been known that individuals' subjective social status, and more generally wellbeing, is dependent on social comparisons to a reference group (Stouffer et al. 1949; Hyman 1960; Wolf 1990). One early source is Stouffer and colleagues' work (1949) on The American Soldier. They found that "soldiers' feelings of deprivation and dissatisfaction were less related to the actual degree of hardship they experienced than to the situation of the unit or group to which they compared themselves" (Delhey and Kohler 2006: 126). Later empirical studies have corroborated the importance of reference groups for both subjective social status (Evans and Kelley 2004; Wolff et al. 2010; Lindemann and Saar 2014; Haught, 
Rose, Geers, and Brown 2015) and income satisfaction (D’Ambrosio and Frick 2007; Liu and Wang 2017).

The issue of reference groups is especially relevant in the case of immigrants because their subjective social status might differ depending on whether their position is compared to the origin or destination societies (Gelatt 2013; Akay et al. 2017; Vaquera and Aranda 2017). Traditionally, research on immigrants' (objective) socioeconomic status has focused on their assimilation into the destination society (Portes and Zhou 1993; Portes and Rumbaut 2001; Alba and Nee 2003). Hence, natives at destination represent the main reference group to which immigrants are compared. However, research in this paradigm has been criticized for truncating immigrants' social trajectories and ignoring their pre-migration experiences (Sayad 1991; Rumbaut 1997: 948). This situation is reinforced by the fact that most largescale representative datasets do not collect information on the status held by immigrants in the origin country.

In this article, we follow a suggestion in Hyman's (1960) classic essay on reference groups and operationalize social status in terms of the amount of education a person has relative to his/her peers. Hyman noted that for older generations, "not to have gone to college is no great deprivation or stigma" while for younger generations, "where higher education is commonplace, to be uneducated may really degrade the self, and to be educated may provide little or no distinction" (p. 390). A similar argument can be applied to national contexts that differ in aggregate educational attainment (Feliciano 2005). While it has become relatively common to employ individuals' educational rank at origin as a proxy for pre-migration status (Ichou 2014; Spörlein and Kristen, 2018; Engzell 2019), here we extend the same approach to the destination country (cf., Feliciano and Lanuza 2017; Ichou and Wallace, 2019). We focus on two outcomes that are likely to be sensitive to reference group considerations: subjective social status and perceived financial situation. In our hypotheses below, we refer to 
"self-perceived status"; to be clear, we use this term to refer to both subjective social status and perceived financial situation.

The origin country as a reference frame

According to what Gelatt (2013) calls "foundational theories of international migration" (i.e., Piore 1979; Stark 1991), immigrants' subjective well-being and social status in the destination country are mostly determined through comparisons to natives in their home country, rather than in the destination. In line with this expectation, Akay et al. (2017) show that immigrants' subjective well-being is affected by changes in their home country's GDP and thus state that "home countries indeed act as a natural comparator for migrants" (353).

Prior research, then, suggests that the origin society is likely to constitute an important reference point for immigrants when they think about their subjective social status (Sayad 1991; Gelatt 2013; Akay et al. 2017; Vaquera and Aranda 2017). Specifically, immigrants' educational selectivity - reflecting their material and social resources in the origin country and, in turn, their social expectations (Feliciano 2005; Ichou 2014; Lee and Zhou 2015; Engzell 2019) - is likely to shape their subjective social status after migration. As Ichou (2014: 751-752) states, "immigrants with a high relative education in their country of origin are likely to see themselves as having a high social status."

Hypothesis 1 (H1): Selectivity hypothesis - Holding current socioeconomic status constant, a high relative position in the origin country will be associated with higher self-perceived status. This expectation rests on the power of socialization processes in the origin country that would durably shape the way immigrants perceive the world and their position within it. 


\section{Transnational status inconsistency}

In the wake of the migrant transnationalism literature (Basch, Glick Schiller, and Szanton Blanc 1993; Vertovec 2004), other research argues that immigrants' frame of reference is better conceived as dual: migrants maintain strong relations with their home society, while at the same time developing links to the host society (Gelatt 2013). Directly relevant to our setting is the fact that migrants often have very different social positions at origin and destination. Indeed, in line with what Nieswand (2011) termed the "status paradox of migration," immigrants often experience a transnational status inconsistency, where pre- and post-migration social statuses diverge (Finnan 1981; Gans 2009).

We are not aware of empirical research analyzing the implications of transnational status inconsistency for migrants' self-perceived status, as we aim to do here. However, one recent paper shows that status inconsistency between one's perceived standing in society and one's standing in more local hierarchies has discernible consequences for mental well-being (Andersson 2018). Thus, what matters may not be immigrants' position in their origin country per se as much as the comparison between their prior and current positions. Hypothesis 2 (H2): Social comparison hypothesis - Holding current socioeconomic status constant, a gain (or loss) in relative position from the origin to the destination country will be associated with higher (or lower) self-perceived status. This hypothesis is based on the premise that immigrants' pre-migration social position is an important reference point from which perceptions about their current social and financial situation are formed.

\section{The burden of positional loss}

The previous hypothesis does not take into account a possible asymmetry between upward and downward comparisons. In Europe and North America, the dominant form of 
transnational status inconsistency appears to be migrants' downward mobility from origin to destination. Anecdotal evidence of this trend is abundant in the form of stories about immigrant professionals making their living as cab drivers, cleaners, or assistant nurses (e.g., The Toronto Star 2007; The Globe and Mail 2012; Der Spiegel 2013). Downward mobility is also documented in the empirical literature on migrants' occupational trajectories (Chiswick, Lee, and Miller 2005; Akresh 2006; Rooth and Ekberg 2006; Obućina 2013b; Simón, Ramos, and Sanromá 2014; Fellini and Guetto 2019).

We could imagine the experience of status loss to have especially strong repercussions for immigrants' self-perception. Migrants with a high status at origin are more likely to experience downward status mobility (or status loss) after migration. Findings suggest that migrants who were highly educated or held high subjective social status at origin have lower levels of well-being at destination (Massey and Akresh 2006; Gelatt 2013; Andersson 2018). These somewhat surprising statistical relationships could be interpreted as the negative consequences of the unfulfilled expectations linked to downward mobility in migration - an interpretation that has not been tested systematically with large-scale data.

Following this logic, we expect status loss to have a specifically negative association with migrants' subjective social status. This hypothesis reflects the more general idea of loss aversion, or that 'losses loom larger than gains' (Kahneman and Tversky 1979). Such an asymmetry has been verified by several empirical studies on income fluctuation within the lifespan (Wolbring, Keuschnigg, and Negele 2011; Boyce et al. 2013), as well as across generations (Dolan and Lordan 2013). Among migrants, downward mobility from origin to destination has been shown to have a specifically negative association with their mental health and well-being (Nicklett and Burgard 2009; Vaquera and Aranda 2017; Euteneuer and Schäfer 2018). Yet, its implications for migrants' self-perceived status remain unknown. 
Hypothesis 3 (H3): Status loss hypothesis - Holding current socioeconomic status constant, a loss will be associated with lower self-perceived status, while a gain in relative position from the origin to the destination country will have little or no association with self-perceived status. This hypothesis is founded on the psychological mechanism of loss aversion, which suggests an asymmetry between upward and downward comparisons.

\section{Empirical Strategy}

Our empirical analyses focus on immigrants to 18 European countries covered in six rounds of the European Social Survey (ESS). The ESS, like most large-scale representative datasets, does not ask immigrants about their social status in their origin country. Our approach, following Hyman (1960), is to use a person's place in the national education distribution relative to others of the same cohort and gender. We calculate similar measures referring to both the origin and destination countries. In addition, we include measures of reported income and social class in the destination country, as well as a range of sociodemographic control variables. In our article's main body, we estimate hierarchical linear models. We prefer these simple models as they are straightforward to interpret and easily allow for graphical display of results. In supplementary analyses, we back up our conclusions, using ordinal models and diagonal reference models proposed in the social mobility literature (Sobel 1981).

Immigrants' educational rank at origin has been used as a predictor in earlier studies, especially in the literature on intergenerational mobility (e.g., Ichou 2014; Feliciano and Lanuza 2017; van de Werfhorst and Heath 2018; Engzell 2019). In line with these studies, we interpret educational selectivity as a proxy for pre-migratory social status (see H1). Yet, if status inconsistency from origin to destination explains immigrants' self-perceived status 
$(\mathrm{H} 2)$, then the difference between the destination and origin positions is a more theoretically justified measure. Moreover, we allow positive and negative positional differences to have separate associations with our subjective outcomes. This approach is crucial, as our theoretical framework leads us to expect that migrants' experience of transnational status loss will have a specifically strong impact on their self-perceived status (H3).

\section{Data and Methods}

Data sources: the European Social Survey and the Barro-Lee dataset

This study pools six waves of the ESS (ESS 2002, 2004, 2006, 2008, 2010, and 2012). We restrict our sample to countries that host a substantial number of immigrants (at least 100 foreign-born individuals in the pooled dataset) and in which immigrants come from a diversified range of origin countries. This first restriction produces an analytical sample comprising immigrants in 18 destination countries (Austria, Belgium, Cyprus, Denmark, Finland, France, Germany, Great Britain, Greece, Ireland, Italy, Luxembourg, the Netherlands, Norway, Portugal, Spain, Sweden, and Switzerland) from 136 origin countries. In addition, we employ information from the Barro-Lee Dataset on Educational Attainment in the World (Barro and Lee 2013), described in greater detail below. ${ }^{1}$

We further restrict our sample to respondents who migrated at age 25 or later to ensure that the education level on record is likely to have been attained in the origin country, not after migrating. Table 1 displays selected descriptive statistics on the resulting sample. After removing missing values on key variables of interests in our regression analyses, we are

\footnotetext{
${ }^{1}$ A small number of origin countries in our data are not represented in the Barro-Lee data. Of these, only three (Bosnia, Georgia, Macedonia) contribute more than a handful of cases, and we impute distributions for those three countries as population-weighted averages of the surrounding region. We also impute values for Yugoslavia as a population-weighted average of its successor states. Our estimates are robust to the exclusion of these cases $(\mathrm{N}=239)$.
} 
left with 5,473 observations. We ascertained that these cases did not differ markedly on the outcomes of interest; respondents with complete data were slightly positively selected on subjective social status and perceived financial situation, but the mean values after selection differed from those for the full sample reported in Table 1 only by 0.02-0.03 standard deviations.

Table 1: Descriptive statistics on the sample of immigrants in the European Social Survey.

\begin{tabular}{|c|c|c|c|c|c|}
\hline Variable & $\mathrm{N}$ & Mean & SD & Min & Max \\
\hline Subjective social status* & 1,083 & 5.57 & 1.72 & 0 & 10 \\
\hline $\begin{array}{l}\text { Self-perceived financial } \\
\text { situation }\end{array}$ & 7,716 & 2.99 & 0.9 & 1 & 4 \\
\hline Selectivity & 7,821 & 71.05 & 28.67 & 0.11 & 100 \\
\hline Status difference & 7,821 & -7.47 & 15.4 & -83.06 & 52.77 \\
\hline Status gain & 7,821 & 2.1 & 5.81 & 0 & 52.77 \\
\hline Status loss & 7,821 & 9.57 & 12.78 & 0 & 83.06 \\
\hline ISEI & 7,298 & 42.36 & 18.39 & 10 & 89 \\
\hline Age & 7,935 & 51.36 & 14.56 & 25 & 97 \\
\hline Gender (female) & 7,935 & 0.53 & 0.5 & 0 & 1 \\
\hline Children at home & 7,914 & 0.43 & 0.5 & 0 & 1 \\
\hline Household size & 7,935 & 1.24 & 0.8 & 1 & 11 \\
\hline Discrimination & 7,935 & 0.01 & 0.1 & 0 & 1 \\
\hline Minority status & 7,771 & 0.22 & 0.42 & 0 & 1 \\
\hline Survey country & $\mathrm{N}$ & Percent & $\begin{array}{l}\text { Region of } \\
\text { origin }\end{array}$ & $\mathrm{N}$ & Percent \\
\hline Austria & 279 & 3.52 & Western & 3,706 & 46.7 \\
\hline Belgium & 496 & 6.25 & East Europe & 1,996 & 25.15 \\
\hline Switzerland & 1,158 & 14.59 & Asia & 653 & 8.23 \\
\hline Cyprus & 132 & 1.66 & Middle East & 659 & 8.3 \\
\hline Germany & 661 & 8.33 & Africa & 358 & 4.51 \\
\hline Denmark & 237 & 2.99 & Latin America & 563 & 7.1 \\
\hline Spain & 551 & 6.94 & Total & 7,935 & 100 \\
\hline Finland & 139 & 1.75 & & & \\
\hline France & 477 & 6.01 & Round & $\mathrm{N}$ & Percent \\
\hline Great Britain & 614 & 7.74 & 1 & 1,544 & 19.46 \\
\hline Greece & 374 & 4.71 & 2 & 1,457 & 18.36 \\
\hline Ireland & 779 & 9.82 & 3 & 1,292 & 16.28 \\
\hline Italy & 62 & 0.78 & 4 & 1,445 & 18.21 \\
\hline Luxembourg & 482 & 6.07 & 5 & 1,081 & 13.62 \\
\hline Netherlands & 381 & 4.8 & 6 & 1,116 & 14.06 \\
\hline Norway & 353 & 4.45 & Total & 7,935 & 100 \\
\hline Portugal & 187 & 2.36 & & & \\
\hline Sweden & 573 & 7.22 & & & \\
\hline Total & 7,935 & 100 & & & \\
\hline
\end{tabular}

*Only available in round 6 
We test our hypotheses, using two related outcomes: respondents' view of their current place in the social hierarchy (subjective social status) and their level of satisfaction with their present income (perceived financial situation). The first item is most appealing from our theoretical viewpoint but unfortunately was only asked in one round $(\mathrm{N}=1,083){ }^{2}$ The second is repeated throughout all rounds $(\mathrm{N}=7,716)$.

The social status question asks respondents to rank themselves on a 0-10 scale from "top" to "bottom" in terms of where in society they feel they currently stand. This measure originates from the 'self-anchoring ladder' devised by Cantril (1965) and has been used in numerous studies since (e.g., Evans and Kelley 2004; Lindemann and Saar 2014; and references therein). The question about perceived financial situation asks respondents to rate how they get by on their household's current income on a four-point scale from "living comfortably" to "finding it very difficult."

Nonresponse to these attitudinal indicators is strikingly low, suggesting that the questions were meaningful to respondents and that respondents did not find them difficult to answer. In our sample, only $3.1 \%$ (social status) and $2.8 \%$ (financial situation) of respondents gave no valid response. In our data, the two variables are moderately correlated (Spearman's $\rho=0.38$, Pearson's $r=0.38$ ). This correlation is not surprising, given that previous work has argued that perceived financial situation is an important constituent of subjective social status (Singh-Manoux, Adler, and Marmot 2003). Both constructs require a self-assessment of respondents' socioeconomic situation relative to an implicit reference group (Wolff et al. 2010; Obućina 2013a; Lindemann and Saar 2014; Liu and Wang 2017). We therefore see them as proxying the same concept of self-perceived status.

\footnotetext{
${ }^{2}$ Of the 18 destination countries included in the analyses, three did not take part in round 6 of the European Social Survey in which subjective social status was measured (Austria, Greece, Luxembourg).
} 


\section{Predictor variables}

To calculate our proxy measures for origin and destination status, we use the Barro-Lee dataset (2013), which compiles international data on educational distributions in 146 countries. This dataset, constructed from data assembled by UNESCO, Eurostat, and other sources, codes the distribution of educational attainment in the adult population by gender and five-year age group in seven categories (no formal education, incomplete primary, complete primary, lower secondary, upper secondary, incomplete tertiary, and complete tertiary education) from 1950 to 2010 by five-year periods. In the ESS data, we draw on the most detailed educational classification available in each survey country and create a variable harmonized with the Barro-Lee categories (see online appendix).

Using this information, we then construct an individual-level measure of immigrants' relative level of educational attainment in their origin country, ranging from 0 to 100. Following earlier contributions, we define the origin country's reference group as people born in the same year and of the same gender (Ichou 2014, Feliciano and Lanuza 2017, Engzell 2019). Barro and Lee (2013) report educational attainment distributions by 5-year cohorts, so to obtain a distribution specific to each birth year, we interpolate distributions linearly to span the intermediate years within each 5-year groups. Formally, we sum the proportion of people in the reference group at origin with a lower education level, plus half those with an identical level:

$$
\pi_{i}^{\text {orig }}=\left(\sum_{j^{*}<j} p_{j^{*}}^{\text {orig }}+\frac{1}{2} p_{j}^{\text {orig }}\right) \times 100
$$

where $p_{j}^{\text {orig }}$ denotes the proportion with education level $j$ in the person's gender and cohort at origin and $j^{*}$ denotes any level lower than $j$. We use this measure to test our first hypothesis 
(the selectivity hypothesis). We also calculate the same measure relative to destinationcountry distributions:

$$
\pi_{i}^{d e s t}=\left(\sum_{j^{*}<j} p_{j *}^{d e s t}+\frac{1}{2} p_{j}^{d e s t}\right) \times 100
$$

where similarly, $p_{j}^{\text {dest }}$ denotes the proportion in the destination country of the same gender and birth cohort with education level $j$ and $j^{*}$ any level that is lower. We then calculate the difference between the two: $\Delta_{i}=\pi_{i}^{\text {dest }}-\pi_{i}^{\text {orig }}$ to test our second hypothesis (the social comparison hypothesis). Finally, to test our third hypothesis (the status loss hypothesis), we separate this difference into gains and losses by creating the following two variables:

$$
\begin{aligned}
& \operatorname{gain}_{i}=\left\{\begin{array}{l}
\left|\Delta_{i}\right| \text { if } \Delta_{i}>0 \\
0 \text { otherwise }
\end{array}\right. \\
& \text { loss }_{i}=\left\{\begin{array}{l}
\left|\Delta_{i}\right| \text { if } \Delta_{i}<0 \\
0 \text { otherwise }
\end{array}\right.
\end{aligned}
$$

Figure 1 illustrates the two measures and how they relate to each other, using our actual data. Along the horizontal axis is the relative position at origin, while along the vertical axis is that at destination. As the marginal histograms show, immigrants in the ESS are on average highly educated by the standards of both origin and destination countries. As a note of caution, these marginal distributions are likely to be somewhat positively biased; survey nonresponse tends to vary inversely with education (Korkeila et al. 2001), and over-reporting of education is also known to occur (Black, Sanders, and Taylor 2003). That most individuals are located below the 45-degree diagonal, however, indicates that status loss as we have operationalized is prevalent. 


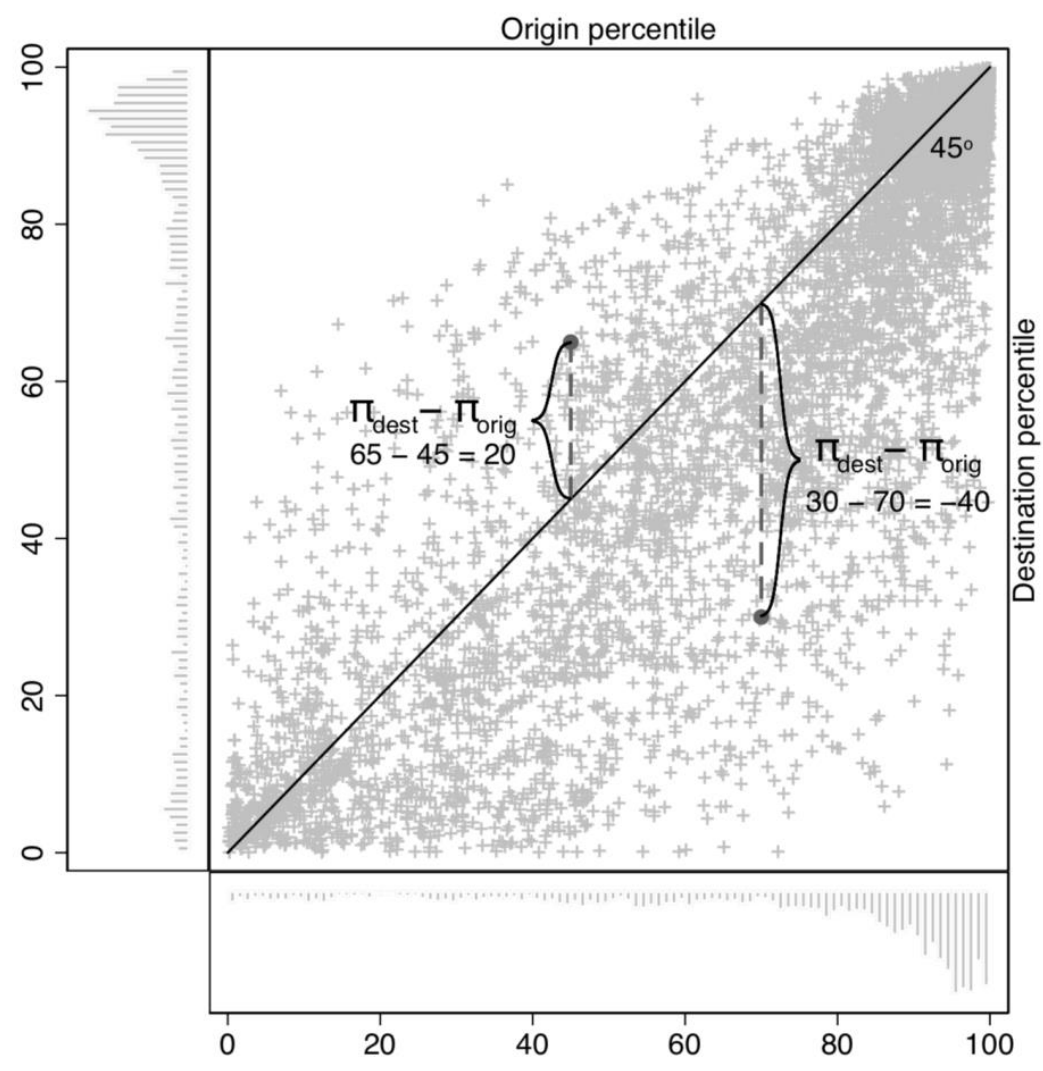

Figure 1: Scatterplot of relative education at origin and destination of immigrants in ESS waves 1-6, with two cases of status difference (status loss and status gain) overlaid for illustration. $\mathrm{N}=7,821$.

\section{Control variables}

To test our three hypotheses, we use multivariate models controlling for measures of immigrants' demographic and socioeconomic characteristics in the destination country. Our control variables are chosen because they are likely to be correlated with both our explanatory variables of interest and the two subjective outcomes. The idea is that we want to compare immigrants who share the same objective circumstances to see whether their evaluation of these circumstances differ depending on their origin position as proxied by our relative education measure. Note, however, that some of these control variables might lie on 
the causal path between independent and dependent variables and are likely to constitute 'overcontrols' in that they block the path between the two. The simpler models, which only control for objective measures of current socioeconomic status (SES), might therefore be considered the most relevant tests of our hypotheses.

Socioeconomic control variables are respondents' current occupational status, measured on the continuous ISEI scale (Ganzeboom, de Graaf, and Treiman 1992) and standardized to mean=0, s.d.=1; social class, measured following the EGP scheme in 11 categories (Erikson, Goldthorpe, and Portocarero 1979); and current income (in deciles). Demographic control variables include respondents' age and age squared; gender; marital status; whether there are children in the household; and household size and its square root (to bring the income measure closer in line with an indicator of equivalized disposable income, using OECD methodology, see OECD 2008). Finally, we include two additional control variables: whether the respondent reports belonging to an ethnic minority in the destination country and whether the respondent reports feeling discriminated against on the basis of ethnicity, skin color, race, or religion. The rationale behind these last two control variables is that racialization and discrimination are known to affect both immigrants' actual socioeconomic status and self-perceptions (Nieswand 2011: 137; Safi 2010).

\section{Results}

\section{Descriptive results}

Figures 2 and 3 display the distributions of immigrants' selectivity (relative educational position at origin) and credential devaluation (the positional difference between origin and destination) by origin regions and destination countries. Figure 2 confirms the finding from previous studies that most migrants are positively selected (Feliciano 2005; van de Werfhorst 
and Heath 2018): they are more educated than the median individual with their characteristics in the origin country. This finding varies substantially across destination countries, however. In some, including Spain, Greece, Italy, and Luxembourg, there are signs of more neutral selection. In other cases, such as Great Britain or Sweden, selectivity appears to be bimodal.
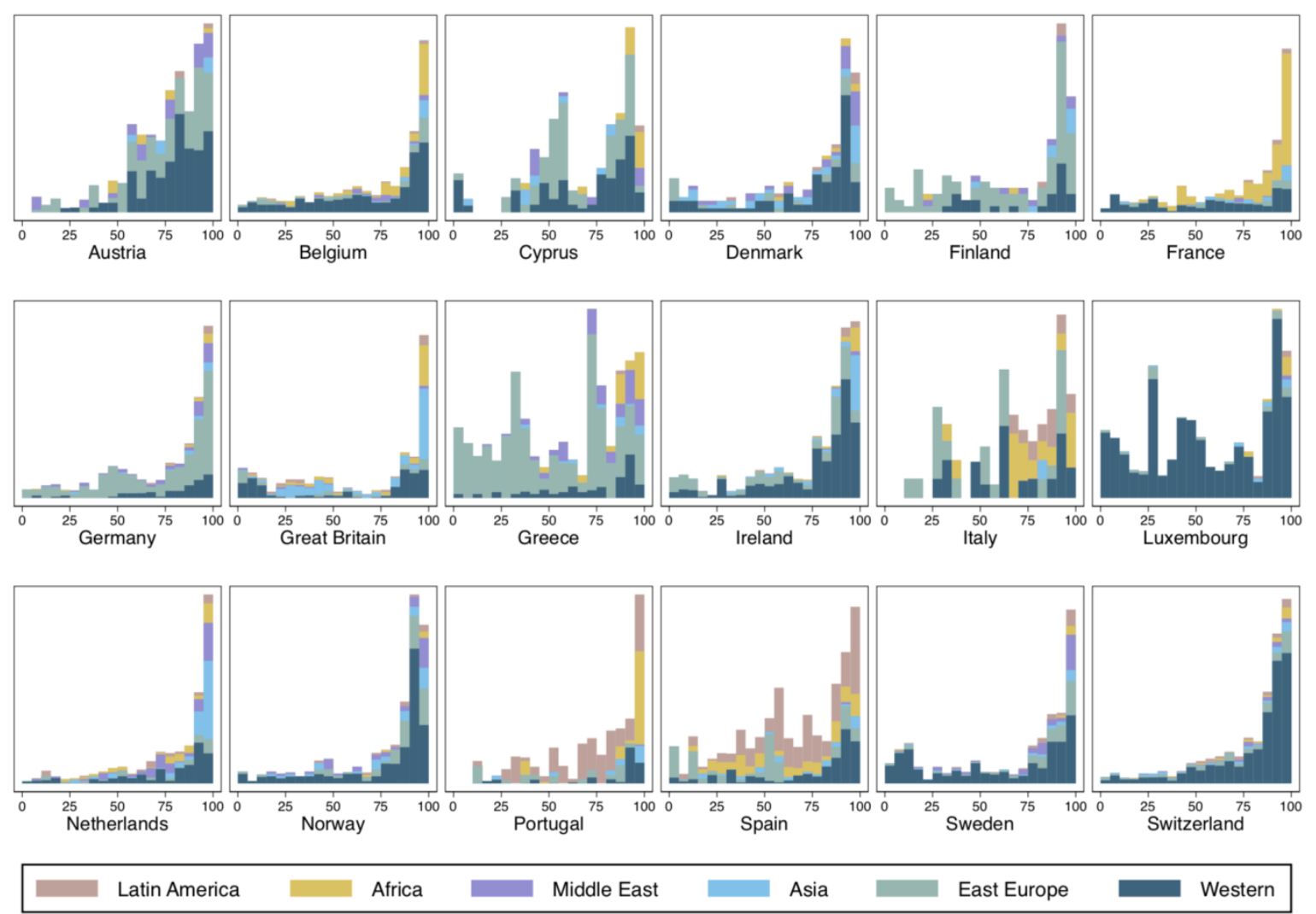

Figure 2: Histogram of relative education at origin by destination country (panels) and region of origin (colors). Own calculations from ESS waves 1-6. ESS design weights applied.

$$
\mathrm{N}=7,821 \text {. }
$$



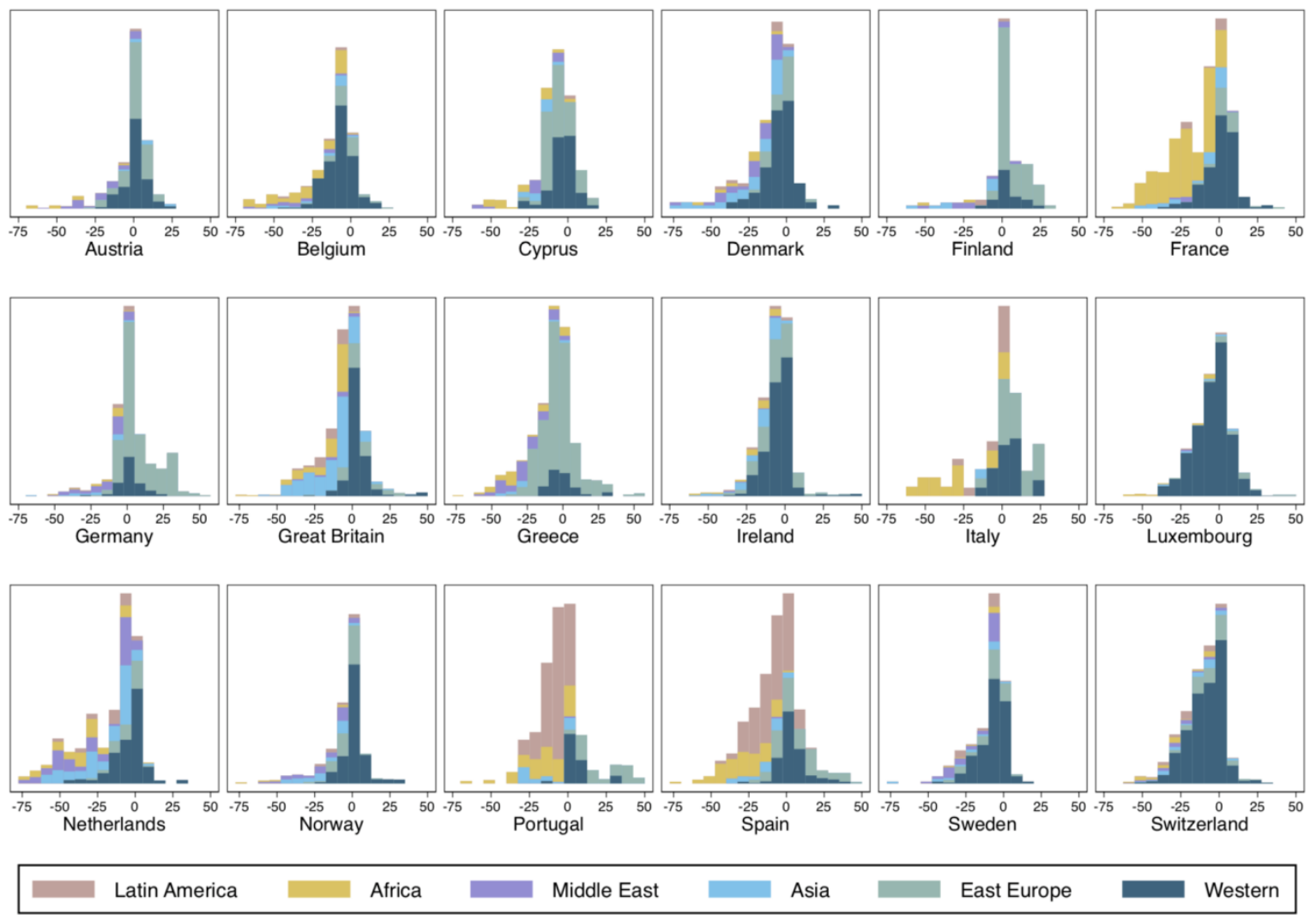

Figure 3: Histogram of status difference - relative education at destination minus that at origin - by destination country (panels) and region of origin (colors). Own calculations from ESS waves 1-6. ESS design weights applied. $\mathrm{N}=7,821$.

Figure 3 displays the positional difference between origin and destination for the reported education level. There is a peak around 0 for all destinations, indicating that a nontrivial fraction of migrants do not experience a large difference between their relative positions at origin and destination. This finding reflects the fact that much of European immigration occurs between countries that are similar in educational distributions. On both sides of the midpoint of no positional difference, however, there is considerable variation. Some countries are largely symmetric around it, whereas others display a long left tail, indicating that credential devaluation (and, we have assumed, status loss) is common. This is the case in 
destinations such as Spain, France, and Portugal, all countries with large immigration from Latin American or African countries.

Overall, Figures 2 and 3 provide an original descriptive account of migrants’ characteristics in Europe that takes into account their dual social position between origin and destination countries. The main message from these figures is, first, that most immigrants are positively selected and, second, that a large fraction experience some form of status inconsistency, especially status loss - in the form of credential devaluation - from origin to destination. In the next section, we analyze the implications of these patterns for immigrants' social and financial self-perceptions.

\section{Regression results}

As a preliminary step to multivariate modelling, we construct Figure 4, in which we link immigrants' transnational status inconsistency to our two outcomes of interest. Figure 4 relates the residuals of subjective social status (after controlling for current occupational status) and perceived financial situation (after controlling for current income) and allows for non-linearity in the relationships. It provides a striking visual clue of (a) the nonlinear relationship linking immigrants' transnational status inconsistency and self-perception and (b) the similarity of the association of transnational status inconsistency with the two subjective outcomes considered. These preliminary graphical results are in line with our third hypothesis (the status loss hypothesis). 


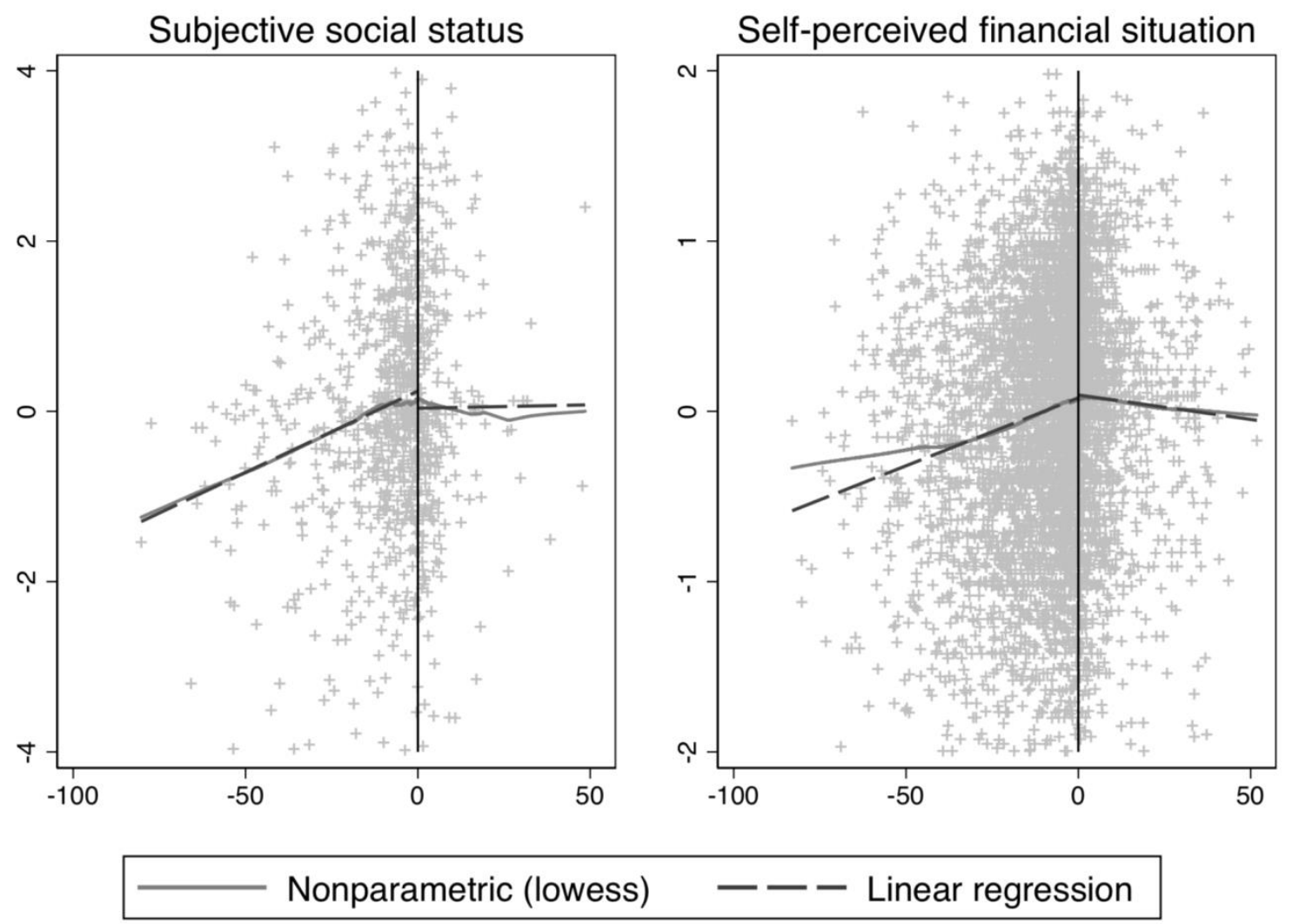

Figure 4: Scatterplot of status difference and both outcomes: subjective social status and perceived financial situation, with superimposed linear and nonparametric (lowess) regression lines. Status difference is displayed along the $\mathrm{x}$-axis, while the $\mathrm{y}$-axis displays unstandardized values of each of the dependent variables residualized for occupational status (in the case of subjective social status) and income (in the case of perceived financial situation). The y-axes have been truncated to the nearest integer, leaving a small number of cases $(2.0 \%$ left panel, $0.8 \%$ right panel) outside the plotting region. $\mathrm{N}=952$ (left), $\mathrm{N}=$ 5,920 (right).

To test our three hypotheses more conclusively, we estimate a set of linear regressions, using random-intercept multilevel modeling, where the higher level is defined by immigrants' destination country. For each hypothesis, we employ three nested models on 
both outcomes of interest. A first baseline model controls only for current socioeconomic status, measured as present income, occupational status, and social class. The second model further controls for whether the respondent holds a university degree, respondent's age and age-squared, gender, marital status, whether there are children in the household, the household size and its square root, whether the respondent reports belonging to an ethnic minority and whether the respondent feels discriminated against. Finally, Model 3 adds immigrants' origin region in six categories as fixed effects. We distinguish between the same six regions shown in Figures 2 and 3: Latin America, Africa, the Middle East, Asia, Eastern Europe, and Western countries.

As the scale of the dependent variables is not inherently meaningful, we standardize them over the whole sample $($ mean $=0$, s.d. $=1)$. For the relative education measures, we divide the percentile scores by 25 to capture a difference of one quartile. This approach is broadly comparable to the standard deviation of the percentile at origin, $\pi_{i}^{\text {orig }}($ s.d. $=28.5)$, while the standard deviation of the positional difference, $\Delta_{i}$, is about two thirds that size (s.d. $=15.5)$. We prefer using this fixed standardization for the percentile measures over the $\mathrm{z}$ standardization used for the dependent variables, since this way they can be interpreted on the same common scale. All associations are estimated using linear regression. In an online appendix, we provide alternative estimates using ordinal logistic regression and diagonal reference models. To economize on space, we do not report coefficients for control variables here, but these too are available in the online appendix.

Table 2 shows the results for our tests of $\mathrm{H} 1, \mathrm{H} 2$, and $\mathrm{H} 3$. In a first set of analyses (Model 1), we use immigrants' relative educational position in their origin country $\left(\pi_{i}^{\text {orig }}\right)$ as the main predictor to test $\mathrm{H} 1$, the selectivity hypothesis. Recall that this hypothesis predicts that over and above current socioeconomic status, a high relative educational position in the origin country will be associated with higher subjective social status and perceived financial 
situation. The models estimated provide little support for this hypothesis: there is virtually no association with either subjective social status or perceived financial situation.

In further analyses presented in Table 2 (Model 2), we include the measure of positional difference $\Delta_{i}$ as the main predictor to test the social comparison hypothesis (H2). The models show a relatively robust positive association with the two outcomes under study. In other words, the larger immigrants' status loss is from origin to destination, the lower the subjective social status and perceived financial situation. Symmetrically, these models would imply that the extent of potential status gains from origin to destination similarly translates into equally higher self-perceptions. This finding is consistent with the comparison mechanism postulated in $\mathrm{H} 2$. 
Table 2: Multivariate linear regression results for three sets of models predicting subjective social status and perceived financial situation. Model 1 tests H1: Selectivity hypothesis;

Model 2 tests H2: Social comparison hypothesis; Model 3 tests H3: Status loss hypothesis.

Subjective social status (std.) Perceived financial situation (std.)

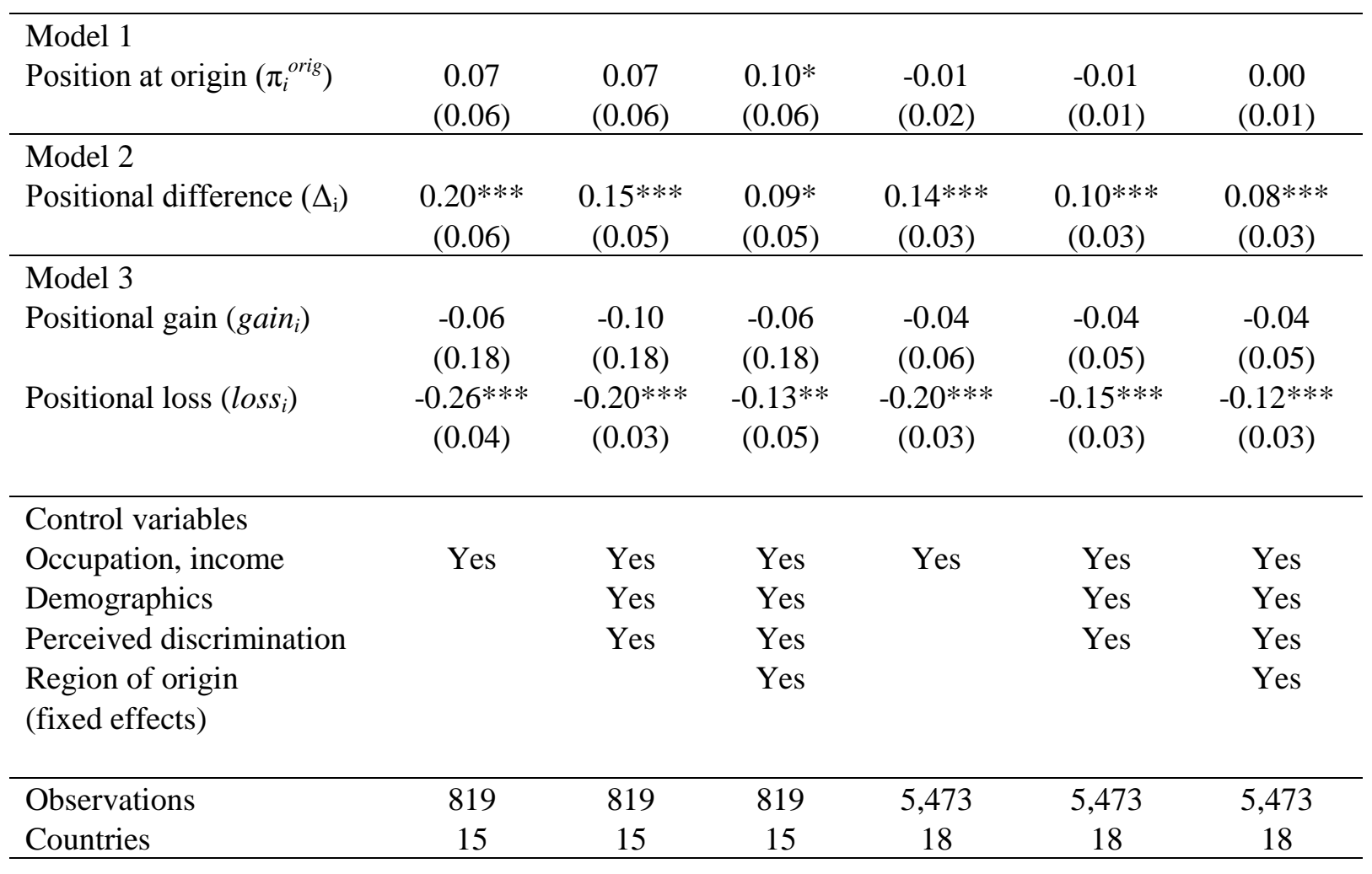

Robust standard errors in parentheses $* * * \mathrm{p}<0.01, * * \mathrm{p}<0.05, * \mathrm{p}<0.1$ 
Because the previous model contains only one linear measure of status difference $(\Delta \mathrm{i})$, status losses and gains are constrained to have the same association. We now test $\mathrm{H} 3$ by entering loss and gain as two separate variables to assess their relative contribution. Model 3 displays the results of this third set of analyses. The linear association assumed in the previous regressions turns out to mask a clear asymmetry, in line with the status loss hypothesis (H3) and as already evident in Figure 4. Migrants who have experienced a gain in relative education moving from their origin country do not report higher subjective social status or perceived financial situation. However, those who have experienced transnational status loss according to this measure tend to report lower subjective outcomes.

The coefficients in Model 3 imply that a 25-percentile point loss of relative educational status is associated with $26 \%$ of a standard deviation lower subjective social status or $21 \%$ of a standard deviation lower perceived financial situation in the most parsimonious models we estimate (controlling only for current occupational status, social class, and income). This amount diminishes to $13 \%$ of a standard deviation in the model with the most extensive controls. Keep in mind that in this last model we condition not only on an extensive set of intermediate variables but also on origin region, while between-country differences in educational composition are the source of variation in our main predictor. We are thus stretching the data's limits, and some of the more parsimonious models might be regarded as more appropriate tests of our hypotheses.

\section{Robustness analyses}

We performed a number of alternative analyses that we report here. First, we have preferred a multilevel linear regression specification which assumes interval-level measurement whereas 
our outcomes are, strictly speaking, ordinal. In the online appendix, we show estimates of all models using ordinal logistic regression, and the results are similar.

Next, we want to exclude the possibility that our results are driven by any single country, which could be important given that some ESS countries may represent quite particular immigration regimes that are unrepresentative of the broader sample. Here we reestimate our preferred model (Model 3, column 1), excluding individual destination and origin countries one at a time, and plot the resulting coefficient for status loss on each outcome. Figure 5, top panel, displays the coefficient for status loss on each outcome in a set of 18 regressions, each with one survey country dropped from consideration. The bottom panel reports a similar exercise in turn dropping each of the 136 origin countries from the estimation. No single country generates a notable change when excluded from the regression, which suggests that our results are broadly generalizable across the countries studied.

Lastly, there is a difficulty in our approach owing to the fact that the positional difference that we take as our main predictor is a perfect linear combination of the positions at origin and destination. This situation makes it impossible to estimate models including all these terms at once. We have diverted that problem here by simply excluding the rank at origin and destination when using the positional difference. However, an alternative solution is the so-called diagonal reference model proposed by Sobel (1981) and implemented by Kaiser (2018). This approach requires categorical data, causing us to split our percentile measure into tertiles, and we regard the estimates as coarser and less informative for that reason. Nevertheless, estimates from these models, reported in the online appendix, support our conclusions. 

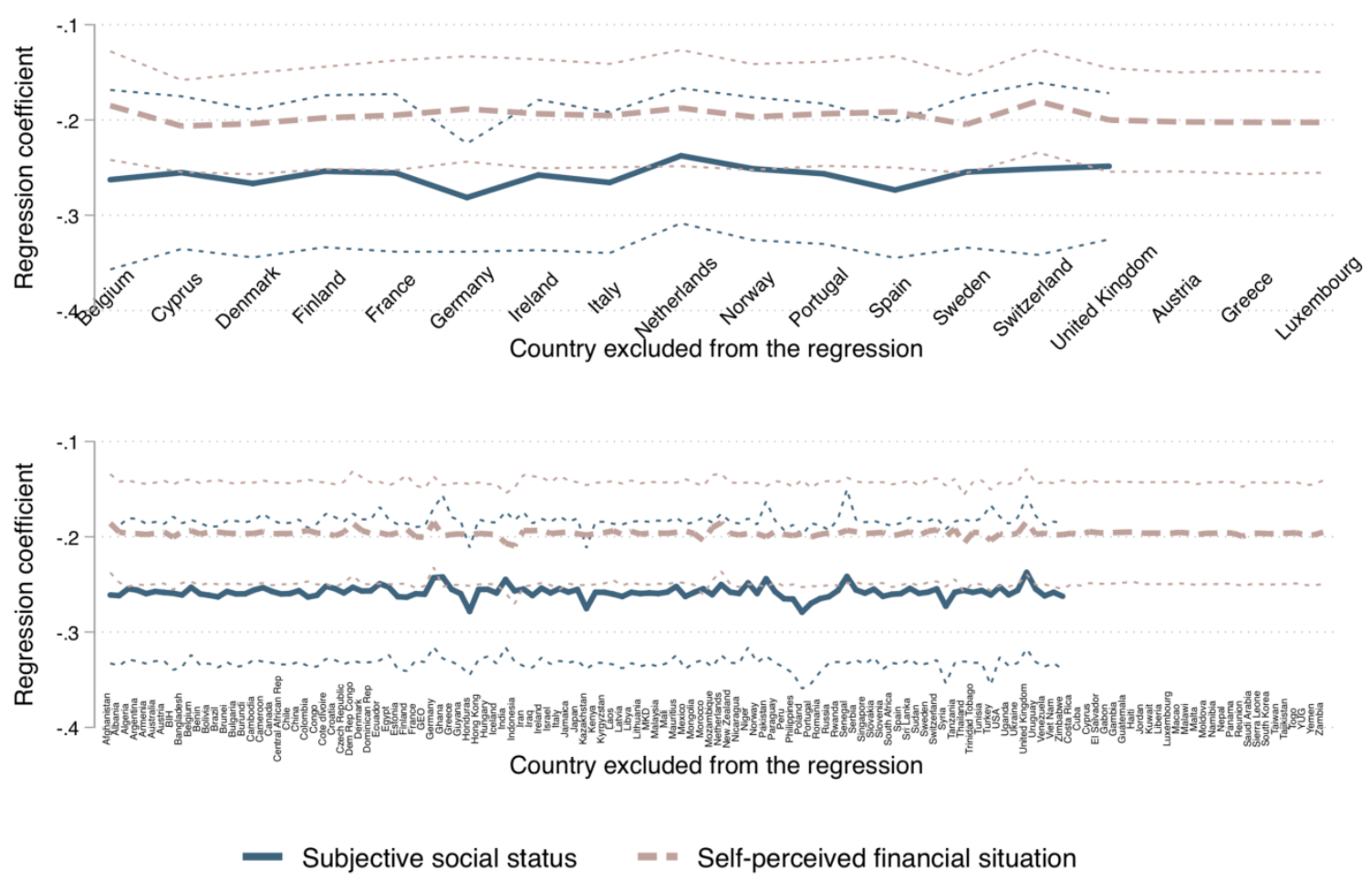

Figure 5: Robustness to the exclusion of single destination and origin countries. The graph depicts recalculated coefficient estimates for status loss from Model 3, column 1, from a set of regressions successively dropping all observations from a single destination country (top) and origin country (bottom) at a time.

\section{Discussion}

Immigration is widely seen as a profound challenge facing wealthy countries today. As European societies are striving to integrate newly arrived populations - often from quite disparate cultural or institutional origins - questions are revived about whether these groups will assimilate into the economic mainstream or come to form a permanent underclass with uncertain implications for receiving societies' social cohesion. In this article, we have argued that to understand immigrants' situation properly, we must grasp both their own perceptions of their position in the new society and the life they have left behind in migrating. 
As a step in this direction, we studied immigrants' self-perceived status - measured as subjective social status and perceived financial situation - that we linked to their relative place in educational distributions of the sending and receiving countries. Our findings can be summarized as follows. First, positional loss in educational rank from origin to destination is by far the most common experience. While this finding is hardly surprising, our original description helps document the full extent of this phenomenon, using representative data. Second, such positional loss matters for the subjective outcomes we study: among immigrants in otherwise-similar circumstances, those higher educated by origin-country than host-country standards make more dismal assessments of their situation. Thus our main finding is that transnational status loss (downward social mobility in migration) is associated with poorer self-perceived status and economic standing, over and above current economic conditions.

In a very broad sense, the findings in this article prompt a reorientation of assimilation scholarship to consider immigrants' social position before migration as a reference point for their broader integration. The assimilation paradigm (Portes and Zhou 1993; Portes and Rumbaut 2001; Alba and Nee 2003), in both its old and new versions, focuses almost exclusively on the destination society, once the individuals under study have immigrated. Our analysis highlights the need to focus on pre-migration characteristics to explain postmigration outcomes and to conceptualize migration as an instance of social mobility - not merely a geographic move. This perspective calls for a reorientation of research toward the existence that migrants have left behind in their origin country.

As for existing scholarship on immigrant selectivity, these results shed new light on established narratives. The fact that immigrants often come from socially advantaged groups in their origin society (positive selection) is usually seen as a resource, almost universally protective of inferior status attainment and worse health outcomes. This perspective is partly 
backed by empirical evidence (Feliciano 2006; Ichou 2014; Kennedy, Kidd, McDonald and Biddle 2015). However, we present a sobering corrective to the dominant optimistic perspective. Our findings imply that the hopes and expectations associated with high premigration status might be shattered by the difficult realities at destination. Undoubtedly, high educational selectivity may give people the assets and desire to seek opportunities of advancement. However, success depends on crucial factors like the transferability of human capital and the context of reception. By raising the stakes, educational selectivity may provide opportunities for great success - or great frustration.

Our findings can also help explain some puzzling findings in the study of integration. While we have studied immigrants' self-perceptions, ultimately, these perceptions will guide behavior and thereby affect social and economic integration. As one example, consider the common finding that children of immigrants are more advantaged in educational ambitions and attainment than more distant descendants of immigrants (Kao and Tienda 1995; Perreira, Harris, and Lee 2006). This finding has often been explained with a fadeout of the inherited "immigrant ethos" in third and higher generations (Rumbaut 1999:181). Our perspective suggests that another facet of the immigrant experience that may fade and give rise to this pattern is the salience with which social status in the origin country is invoked as a reference for social comparison (see Feliciano and Lanuza 2017). In the same way that children of nonmigrants who have experienced downward intergenerational social mobility tend to regain status in a process of “counter-mobility” (Girod 1971; Bertaux 1974; Goldthorpe 1980), children of immigrants are likely to strive to compensate for their parents' lost status.

The analyses displayed here demonstrate the usefulness of our theoretical framework and point toward a fruitful new direction in research on migration and assimilation, but they have inevitable limitations. For example, the design entails that the status inconsistency we can measure stems from one dimension of status only: educational attainment. However, 
social status is not reducible to relative educational position, nor is transnational status loss attributable only to credential devaluation. Our empirical strategy is guided by feasibility, as direct information on pre- and post-migration social status is not available in representative, cross-country data of the type we use here. Insofar as better data are likely to become available in the future, we hope that the hypotheses we have advanced will be put to a more rigorous test.

\section{References}

Abraído-Lanza, A. F., S. E. Echeverría, and K. R. Flórez. 2016. "Latino immigrants, acculturation, and health: Promising new directions in research." Annual Review of Public Health, 37:219-236.

Akay, A., O. Bargain, and K. F. Zimmermann. 2017. "Home sweet home? Macroeconomic conditions in home countries and the well-being of migrants." Journal of Human Resources, 52(2):351-373.

Akresh, I. R. 2006. "Occupational Mobility among Legal Immigrants to the United States." International Migration Review, 40(4):854-884.

Alba, R., and N. Foner. 2015. Strangers no more: Immigration and the challenges of integration in North America and Western Europe. Princeton University Press.

Alba, R., and V. Nee. 2003. Remaking the American Mainstream: Assimilation and contemporary immigration. Harvard University Press.

Adler, N. E., E. S. Epel, G. Castellazzo, and J. R. Ickovics. 2000. "Relationship of subjective and objective social status with psychological and physiological functioning: Preliminary data in healthy, White women.” Health psychology, 19(6):586. 
Anderson, C., M. W. Kraus, A. D. Galinsky, and D. Keltner. 2012. "The local-ladder effect: Social status and subjective well-being.” Psychological science, 23(7):764-771.

Andersson, M. A. 2015. "How do we assign ourselves social status? A cross-cultural test of the cognitive averaging principle.” Social Science Research 52:317-329.

Barro, R. J., and J. W. Lee. 2013. "A New Data Set of Educational Attainment in the World, 1950-2010.” Journal of Development Economics, 104:184-198.

Basch, L., N. G. Schiller, and C. Szanton-Blanc. 1993. “Transnational Projects of Immigrants and Ethnographers, and the Cultural Politics of Nation-States." Unpublished paper.

Bertaux, D. 1974. "Mobilité sociale biographique : une critique de l'approche transversale." Revue française de sociologie, 329-362.

Black, D., S. Sanders, and L. Taylor. 2003. "Measurement of Higher Education in the Census and Current Population Survey.” Journal of the American Statistical Association, 98(463):545-554.

Borjas, G. J. 1987. "Self-Selection and the Earnings of Immigrants." American Economic Review 77(4): 531-553.

Boyce, C. J., A. M. Wood., J. Banks., A. E. Clark., and G. D. A. Brown. 2013. “Money, Well-Being, and Loss Aversion: Does an income loss have a greater effect on wellbeing than an equivalent income gain?” Psychological Science, 24(12):2557-2562.

Bross, I. D. J. 1958. “How to Use Ridit Analysis.” Biometrics, 14(1):18-38.

Cantril, H. (1965). The Pattern of Human Concerns. Rutgers University Press.

Chiswick, B. R. 1999. “Are Immigrants Favorably Self-Selected?” American Economic Review, 89(2):181-185. 
Chiswick, B. R., Y. L. Lee, and P. W. Miller. 2005. “A Longitudinal Analysis of Immigrant Occupational Mobility: A test of the immigrant assimilation hypothesis.” International Migration Review, 39(2):332-353.

Crul, M., and J. Mollenkopf, eds., 2012. The changing face of world cities: Young adult children of immigrants in Europe and the United States. Russell Sage Foundation.

D’Ambrosio, C., and J. R. Frick. 2007. “Income Satisfaction and Relative Deprivation: An empirical link.” Social Indicators Research, 81(3):497-519.

Engzell, P. 2019. “Aspiration Squeeze: The Struggle of Children to Positively Selected Immigrants.” Sociology of Education, 92(1) 83-103.

Erikson, R., J. H. Goldthorpe, and L. Portocarero 1979. "Intergenerational Class Mobility in Three Western European Societies: England, France, and Sweden.” British Journal of Sociology, 30(4):415-441.

Euteneuer, F., and S. J. Schäfer. 2018. "Brief Report: Subjective Social Mobility and Depressive Symptoms in Syrian Refugees to Germany.” Journal of immigrant and minority health, 1-4.

Evans, M. D., and J. Kelley. 2004. "Subjective Social Location: Data from 21 nations." International Journal of Public Opinion Research, 16(1):3-38.

Feliciano, C. 2005. "Does Selective Migration Matter? Explaining ethnic disparities in educational attainment among immigrants' children.” International Migration Review, 39(4):841-871.

Feliciano, C., and Y. R. Lanuza. 2017. “An Immigrant Paradox? Contextual attainment and intergenerational educational mobility.” American Sociological Review, 82(1):211241. 
Fellini, I., and R. Guetto. 2019. “A “U-Shaped” Pattern of Immigrants' Occupational Careers? A Comparative Analysis of Italy, Spain, and France.” International Migration Review, 53(1) 26-58.

Finnan, C. R. 1981. “Occupational Assimilation of Refugees.” International Migration Review, 15(1/2):292-309.

Gans, H. J. 2009. "First Generation Decline: Downward mobility among refugees and immigrants.” Ethnic and Racial Studies, 32(9):1658-1670.

Ganzeboom, H. B., P. M. de Graaf, and D. J. Treiman 1992. “A Standard International SocioEconomic Index of Occupational Status.” Social Science Research, 21(1):1-56.

Gelatt, J. 2013. "Looking down or looking up: status and subjective well-being among Asian and Latino immigrants in the United States.” International Migration Review, 47(1):39-75.

Girod, R. 1971. "Mobilité sociale : faits établis et problèmes ouverts." Geneva: Droz.

Globe and Mail, The. 2012. "Overqualified Immigrants Really Are Driving Taxis in Canada.” May 10, 2012.

Goldthorpe, J. H. 1980. Social Mobility and Class Structure in Modern Britain. Oxford: Clarendon Press.

Haught, H. M., J. Rose, A. Geers, and J. A. Brown. 2015. "Subjective social status and wellbeing: the role of referent abstraction.” Journal of social psychology, 155(4):356-369.

Heath, A. F., and S. Y. Cheung, eds. 2007. Unequal Chances: Ethnic minorities in Western labour markets. Oxford University Press for the British Academy.

Hyman, H. H. 1960. "Reflections on Reference Groups.” Public Opinion Quarterly, 24(3):383-396. 
Ichou, M. 2014. 'Who They Were There: Immigrants' educational selectivity and their children's educational attainment.” European Sociological Review, 30(6):750-765.

Ichou, M., and M. Wallace. 2019. “The Healthy Immigrant Effect: The role of educational selectivity in the good health of migrants." Demographic Research 40(4): 61-94.

Kahneman, D., and A. Tversky. 1979. "Prospect Theory: An analysis of decision under risk." Econometrica, 47(2):263-292.

Kaiser, C. 2018. DRM: Stata module to fit Sobel's Diagonal Reference Model (DRM).

Kao, G., and M. Tienda. 1995. "Optimism and Achievement: The educational performance of immigrant youth.” Social Science Quarterly, 76, 1-19.

Kennedy, S., M. P. Kidd, J. T. McDonald, and N. Biddle. 2015. “The healthy immigrant effect: patterns and evidence from four countries.” Journal of International Migration and Integration, 16(2):317-332.

Korkeila, K., S. Suominen, J. Ahvenainen, A. Ojanlatva, P. Rautava, H. Helenius, and M. Koskenvuo. 2001. "Non-Response and Related Factors in a Nation-Wide Health Survey.” European Journal of Epidemiology, 17(11):991-999.

Lee, J. and M. Zhou. 2015. The Asian American Achievement Paradox. New York: Russell Sage Foundation.

Lindemann, K., and E. Saar. 2014. "Contextual Effects on Subjective Social Position: Evidence from European countries.” International Journal of Comparative Sociology, $55(1): 3-23$.

Liu, K., and X. Wang. 2017. "Relative Income and Income Satisfaction: An Experimental Study." Social Indicators Research, 132(1):395-409. 
Massey, D. S., and I. R. Akresh. 2006. "Immigrant intentions and mobility in a global economy: The attitudes and behavior of recently arrived US immigrants." Social Science Quarterly, 87(5):954-971.

Nicklett, E. J., and S. A. Burgard. 2009. "Downward social mobility and major depressive episodes among Latino and Asian-American immigrants to the United States.” American Journal of Epidemiology, 170(6):793-801.

Nieswand, B. 2011. "Theorising Transnational Migration: The status paradox of migration." New York and Oxford: Routledge.

Obućina, O. 2013a. “Occupational trajectories and occupational cost among Senegalese immigrants in Europe.” Demographic Research, 28, 547-580.

Obućina, O. 2013b. “The patterns of satisfaction among immigrants in Germany.” Social Indicators Research, 113(3):1105-1127.

Perreira, K. M., K. M. Harris, and D. Lee. 2006. "Making it in America: High school completion by immigrant and native youth.” Demography, 43(3):511-536.

Piore, M. J. 1979. Birds of Passage: Migrant Labor and Industrial Society.” Cambridge: Cambridge University Press.

Portes A., and R G. Rumbaut. 2001. Legacies: The story of the immigrant second generation. University of California Press.

Portes, A., and M. Zhou 1993. “The New Second Generation: Segmented assimilation and its variants." The Annals of the American Academy of Political and Social Science, 530(1):74-96.

Rooth, D. O., and J. Ekberg. 2006. "Occupational Mobility for Immigrants in Sweden.” International Migration, 44(2):57-77. 
Rumbaut, R. G. 1997. “Assimilation and Its Discontents: Between rhetoric and reality." International Migration Review, 31(4):923-960.

Rumbaut, R. G. 1999. “Assimilation and Its Discontents: Ironies and Paradoxes.” Ch. 9 in C. Hirschman, P. Kasinitz, and J. DeWind (eds. ):Handbook of International Migration: The American Experience. New York: Russell Sage Foundation.

Safi, M. 2010. 'Immigrants' Life Satisfaction in Europe: Between assimilation and discrimination.” European Sociological Review, 26(2):159-176.

Sayad, A. 1991. L’Immigration ou les paradoxes de l'altérité. Bruxelles: De BoeckUniversité.

Schaeffer, M. 2018. "Social Mobility and Perceived Discrimination: Adding an Intergenerational Perspective.” European Sociological Review, 35(1):65-80.

Simón, H., R. Ramos, and E. Sanromá. 2014. “Immigrant Occupational Mobility: Longitudinal evidence from Spain.” European Journal of Population, 30(2):223-255.

Singh-Manoux, A., N. E. Adler, and M. G. Marmot. 2003. "Subjective Social Status: Its determinants and its association with measures of ill-health in the Whitehall II study." Social Science and Medicine, 56(6):1321-1333.

Sobel, M. E. 1981. "Diagonal mobility models: A substantively motivated class of designs for the analysis of mobility effects.” American sociological review, 893-906.

Spiegel, Der. 2013. “The New Guest Workers: A German dream for crisis refugees.” February 28, 2013.

Spörlein, C., and C. Kristen. 2018. "Educational Selectivity and Language Acquisition among Recently Arrived Immigrants.” International Migration Review, Published Online on October 4, 2018. 
Stark, O. 1991. The Migration of Labor. Cambridge, MA: Basil Blackwell.

Stouffer, S. A., E. A. Suchman, L. C. DeVinney, S. A. Star, and R. M. Williams, Jr. 1949. The American Soldier, Vol. 1: Adjustment during army life (Studies in Social Psychology in World War II. Princeton University Press.

Toronto Star, The. 2007. “A Small Step to Immigration Sanity.” June 1, 2007.

Vaquera, E., and E. Aranda. 2017. "Moving Up and Down the Ladder: Perceived Social Mobility and Emotional Dispositions Among South Florida’s Immigrants.” Sociological Forum, 32(4):793-815.

Vertovec, S. 2004. "Migrant transnationalism and modes of transformation.” International Migration Review 38(3):970-1001.

Wolbring, T., M. Keuschnigg, and E. Negele. 2011. "Needs, comparisons, and adaptation: The importance of relative income for life satisfaction.” European Sociological Review, 29(1):86-104.

Wolf, C. 1990. "Relative Advantage.” Symbolic Interaction, 13(1):37-61.

Wolff, L. S., S. V. Subramanian, D. Acevedo-Garcia, D. Weber, and I. Kawachi. 2010. "Compared to whom? Subjective social status, self-rated health, and referent group sensitivity in a diverse US sample.” Social Science and Medicine, 70(12):2019-2028.

van de Werfhorst, H. G., and A. Heath. 2018. "Selectivity of Migration and the Educational Disadvantages of Second-Generation Immigrants in Ten Host Societies.” European Journal of Population, online first. https://doi. org/10. 1007/s10680-018-9484-2 